\title{
El señuelo patrimonial. Pensamientos post-arqueológicos en el camino de los incas
}

\author{
Cristóbal Gnecco \\ Tunja: Universidad Pedagógica y Tecnológica de Colombia (UPTC) \\ 2019. $180 \mathrm{p}$. \\ Diana Bernal Monroy \\ Universidad Pedagógica y Tecnológica de Colombia (UPTC), Boyacá, Colombia. \\ $\square$ dianabernal564@gmail.com \\ (1) ORCID: 0000-0001-6971-0922 \\ $\approx$ Google Scholar
}

Este libro presenta una discusión sobre la gestión del patrimonio cultural en un ensayo polémico y provocativo de Cristóbal Gnecco. La propuesta de análisis es comentada por siete autores de los países del Camino de los incas. Algunos de los comentaristas hicieron parte del proceso de postulación del Camino de los incas y otros han trabajado y recorrido partes del mismo. El volumen constituye la segunda entrega de la colección Diálogos en Patrimonio Cultural de la Universidad Pedagógica y Tecnológica de Colombia.

Gnecco cuestiona la declaratoria de los bienes de interés cultural y observa sus efectos en las comunidades. Se pregunta acerca de la intencionalidad que subyace al ejercicio de la declaración de dichos bienes: ¿realmente busca conservar y proteger los bienes y saberes que hacen parte de la cultura e identidad de la humanidad? o, por el contrario, ¿se trata de un señuelo por medio del cual se procura introducir políticas neoliberales de desarrollo en rincones hasta el momento muy apartados de dicho contexto? Para adentrarnos en esta discusión, que siempre se ha suscitado en los salones universitarios donde se discuten los estudios patrimoniales, Gnecco expone el caso de un objeto que tiene la particularidad de pertenecer a muchos lugares a la vez: un camino. 
El Qhapaq Ñan, que atraviesa desiertos, valles, montañas y ríos, fue declarado por la Unesco como Patrimonio de la Humanidad en el año 2014, resultando un escenario muy exigente para las apreciaciones de la gestión patrimonial por varias razones; entre ellas, la variedad de tipos de caminos que lo componen, la diversidad de poblaciones que habitan a su vera en los seis países que hacen parte de la postulación del camino y con ello un sin número de acuerdos y desacuerdos en su gestión y manejo.

Cristóbal Gnecco presenta una etnografía del camino con el propósito de entender los efectos de la patrimonialización. Sus observaciones sobre el recorrido no están dirigidas a detallar la arqueología y construcción del camino. En cambio, se refiere al entorno político, a las condiciones sociales, a las representaciones culturales asociadas a la civilización incaica dadas al camino después de su declaratoria y a la vida de las poblaciones tras la declaratoria.

Sobre el camino se impuso una marca como "sistema vial inca". Se trata de la totalización cultural de un lugar por el que transitan flujos de personas pertenecientes a muchos pueblos y lugares. La marca del camino, que parece inofensiva y da la sensación de estar dirigida a dar un valor histórico al camino, tiene, sin embargo, un efecto social y político muy ofensivo para las poblaciones que actualmente habitan el territorio que comprende el Qhapaq Ñan. No se pueden reconocer a sí mismas, ni a sus antepasados, en la inmensa magnitud que representa el pasado de una antigua civilización que construyó ciudades y caminos que cruzan desde la costa hasta las altas cumbres andinas y atraviesan el subcontinente de sur a norte.

Esta marca también se encuentra ligada a un factor comercial y de turismo. El pasado del camino proporciona al visitante la sensación de encuentro con las ruinas de culturas invadidas y mestizadas, convirtiendo a la ruina en un objeto que provoca en sus visitantes nostalgia, en especial cuando ese pasado refleja poder a través de sus grandes e imponentes vestigios. La nostalgia unida a la ruina llama y convoca a ser visitada, se convierte en un viaje de introspección que permite sentir la magia del pasado atropellado.

De tal manera, la declaratoria actúa sobre las comunidades con el doble sentido de: "neutralizar el sentido político y entregar al mercado cultural". La patrimonialización frena las acciones políticas de los pobladores y su curso de vida es desviado hacia intereses comerciales, en especial los del turismo. Es por ello que, en el recorrido del texto, tanto el autor como sus comentaristas hacen referencia a la infraestructura 
turística y hotelera que ha sido construida para mejorar la experiencia del visitante, con la cual se mejoran las condiciones de vida de los pobladores, pero su fin no es necesariamente servir a las comunidades.

Giancarlo Marcone y Rodrigo Ruiz hacen una crítica a la postura de Cristóbal Gnecco acerca de la gestión cultural. En ella no encuentran un diálogo que trascienda la puesta en evidencia de la gestión patrimonial, bajo postulados que critican las declaratorias sin llegar a conclusiones resolutivas. El autor responde que resolver la discusión que se da en torno al patrimonio cultural no se queda necesariamente en cuestiones académicas y de debate, puesto que el patrimonio es un tema político y económico, en el que los estados, y hoy en día los organismos internacionales, deciden qué se conserva, de qué manera y qué destino debe tener el patrimonio.

Desde una postura contraria a la de Gnecco, Victoria Ayelen y Christian Vitry señalan los beneficios de las declaratorias para las comunidades. Un ejemplo es el caso argentino de gestión cultural del camino, donde se ha permitido la participación comunitaria, logrando progresos sociales con el impulso del turismo comunitario, programas de conservación medioambiental y la dotación de fuentes de agua potable y mayor conectividad para las poblaciones alrededor del camino.

Por su parte, Ivana Carina y Alejandra Korstange concuerdan con la noción del señuelo patrimonial que se crea con la patrimonialización, una herramienta posmoderna que busca incluir a las comunidades en los sistemas políticos de desarrollo e incidir en sus economías a través del turismo. Ivanna Carina habla desde el caso de neoextractivismo que pone el camino sobre los mismos sentidos y flujos de proyectos de conexión y extracción de minerales de los países sudamericanos como la IIRSA. Alejandra Korstange argumenta que el patrimonio pone a una clase por encima de la otra llevando comodidades a lugares que nos las tenían para que los turistas puedan estar satisfechos, mientras quienes les sirven continúan en las mismas condiciones de precariedad. Por su parte, Sebastián Jalle hace un importante análisis de la difícil situación del camino en medio de disputas territoriales de campesinos, las antiguas luchas sindicales y la extracción minera. Según el autor, estas coyunturas crean la necesidad de que el patrimonio no sólo esté en cabeza de un ministerio de cultura, sino que sea interdisciplinario y gubernativo desde muchas áreas de gestión y desarrollo de los estados.

El camino es una "idea" construida sobre un imaginario indígena potente, místico y espiritual. Se denomina idea, porque el camino en 
muchas partes deja de ser camino: a veces no está, se ha perdido, cercado o levantado y llevado a un lugar con mejores condiciones para su uso. El camino es una idea que se vende, un lugar que se reconstruye para mostrar los lugares ancestrales incas y al que se le intenta dar vida con las personas que lo recorren día a día; ellos son quienes aportan su sentido de pasado y la nostalgia de la civilización perdida.

Sin embargo, Gnecco y los comentaristas se quedan cortos en reconocer que, incluso antes y al margen de la patrimonialización, el camino había sido conservado por años, puede que no como un camino inca, pero sí como un camino necesario para movilizarse. Esa conservación comunitaria, por cierto, inexplorada en el texto, tiene mucho por enseñarnos acerca las resistencias de las poblaciones y de sus formas de vida junto con el mundo material. A partir de mi trabajo de campo en el camino del Mincho, en Boyacá, Colombia (Bernal, 2019), he encontrado que los caminos tienen una vida que ocurre junto a la de las personas que los caminan, dentro de procesos indeterminados de acciones humanas y de las cosas, en las que el mismo camino puede caminar. Cuando se pierden, desaparecen, crecen o modifican su rumbo o su forma; es su vida cambiante, ambivalente y dinámica la que está ocurriendo. Es así como las acciones globales inciden en las acciones regionales y locales y, por lo tanto, en la vida del camino y de sus poblaciones.

A manera de balance: el aporte del texto es develar los efectos de las declaratorias, que de otro modo parecen inocuas y establecer cuáles son sus direcciones políticas y sociales. También pone de presente las ausencias en los estudios del patrimonio y la necesidad imperiosa de evitar que se convierta en un arma de doble filo para las poblaciones que conviven con su presencia ruinosa. Hago un llamado a encontrar en el patrimonio a un maestro que nos enseñe de los mundos diferentes al nuestro, de vidas que, seguramente, nos harán ser personas diferentes, un maestro con el cual podamos acercarnos a conocimientos que puedan servir en nuestra realidad deshumanizada y a la creación de políticas de factura local y regional.

\section{Referencias bibliográficas}

Gnecco, C. (2019). El señuelo patrimonial. Pensamientos post-arqueológicos en el camino de los incas. Universidad Pedagógica y Tecnológica de Colombia.

Bernal, D. (2019). El Camino del Mincho. Valoraciones culturales del derechazo y el camino que camina hacia un efectivo derecho de las cosas. (Tesis de Maestría). Universidad Pedagógica y Tecnológica de Colombia, Tunja, Colombia. 